\title{
Osseointegration of Innovative Customized Implants in the Tubular Bone (Experimental Study)
}

DOI: $10.17691 / \mathrm{stm} 2017.9 .1 .09$

ReceivedMay 19, 2016

E.N. Gorbach, PhD, Leading Researcher, Laboratory of Morphology';

A.A. Yemanov, PhD, Senior Researcher, Laboratory of Reconstructive Arthroplasty and Arthroscopy';

E.N. Ovchinnikov, PhD, Academic Secretary';

V.P. Kuznetsov, DSC, Professor, Department of Thermal Treatment and Physics of Metals';

Head of the Laboratory of Scientific Researches in Biomechanics and Engineering";

A.S. Fefelov, PhD, Director of the Regional Engineering Center²;

V.G. Gorgots, PhD, Senior Researcher, Laboratory of Scientific Researches in Biomechanics and Engineering';

D.Y. Borzunov, MD, DSc, Deputy Director on Scientific Work';

A.V. Gubin, MD, DSc, Director ${ }^{1}$

TRussian llizarov Scientific Center for Restorative Traumatology and Orthopaedics, 6 M. Ulianova St., Kurgan,

640014, Russian Federation;

${ }^{2}$ Ural Federal University named after the first President of Russia B.N. Yeltsin, 19 Mira St., Yekaterinburg,

620002, Russian Federation

An optimal condition for implant osseointegration is its mechanical stability. However, the process of osseointegration depends on numerous other conditions: mechanical stimulation, implant specific geometry, chemical composition of the surface and its architectonics, topology, and the way of surface relief formation.

The aim of the investigation was to assess the capabilities of osseointegration of implants from stainless steel, fabricated by means of additive manufacturing technologies, for rabbit tibia replacement.

Materials and Methods. The experiment has been carried out on 6 chinchilla rabbits aged 6-8 months. Amputation of the shin was performed to all animals under general anesthesia, and implants, made with the help of additive manufacturing technologies, were screwed in. The stumps, abutments and implants were fixed during 6 weeks by llizarov apparatus. Investigations were performed using clinical, radiographic and histological methods.

Results. The findings obtained testify to the ability of the applied screw construction to osseointegration into the tubular bone structure. Neogenesis of bone tissue on the implant surface after 12 weeks provides formation of a bone-implant block ensuring stable implant position in the tubular bone and capability of enduring mechanical load.

Key words: screw implant; tubular bone; prosthetics; osseointegration.

Intrabone screw implants are being actively used in dentistry and orthopaedics. An optimal condition for osseointegration is a mechanical stability of an implant in the bone [1, 2]. However, this process depends on many factors influencing the interaction of implant with the bone and paraossal tissues. In particular, such disease as osteoporosis or insufficient dietary intake of protein can negatively affect the quality of the compact bone tissue and impair the process of implant osseointegration as well [3]. And conversely, systemic treatment of osteoporosis can improve osseointegration influencing positively the architectonics and composition of the bone tissue being formed around implants contributing to a greater mechanical strength of the forming bone-implant block [4-6].

Mechanical loading on the bone in vivo influences positively the bone mass, promotes the increase of its density and strength, which is confirmed by the data of studying microarchitectures of the lamellar and trabecular bone $[4,5,7]$.

Of great importance for osseointegration are factors of mechanical action exerted by the implant itself (or additional), its specific geometry, chemical composition the surface coating, relief, topology and so on [5]. The way of forming surface relief plays an important role as well. The preferential methods commonly used at present are sandblasting and etching the surface texture, as this kind of treatment ensures a more close contact with the implant compared to other techniques $[8,9]$. The effect of implant insertion on the osseointegration quality is being yet discussed.

There are single publications on the necessity of developing channels in the implant to introduce drugs possessing both antibacterial and osseointegrating properties [10]. This technology was used by us for the first time in the implants for osseointegration. It should

For contacts: Andrey A. Yemanov, e-mail: A_Eman@list.ru 
be noted that fabrication of such channels especially with small-size implants is impossible without additive technologies.

The aim of the investigation was to assess the capabilities of osseointegration of implants from stainless steel, fabricated by means of additive manufacturing technologies, for rabbit tibia replacement.

Materials and Methods. Tubular bone stump implant, fabricated by additive manufacturing technology from the EOS PH1 stainless steel powder (GLW Technology, Canada) using EOSINT 280 system (EOS $\mathrm{GmbH}$, Germany), was developed by us (RF Patent No.152558). Chemically the material was composed of the following elements: $\mathrm{Fe}$ (in norm), $\mathrm{Cr}(18 \%), \mathrm{Ni}(4 \%)$, $\mathrm{Cu}(4 \%), \mathrm{Mn}(1 \%)$, Si $(0.75 \%)$, Mo $(0.5 \%)$, Nb $(0.16 \%)$, C $(0.07 \%)$ (Figure 1$)$.

Mechanical properties were determined as per ISO 6892:1998 (E). The items for test investigations were $5 \mathrm{~mm}$ in diameter, $25 \mathrm{~mm}$ long and were manufactured with a layer thickness of $20 \mu \mathrm{m}$. Ultimate tensile strength in the vertical direction after fabrication and thermal treatment was $1,450 \pm 100 \mathrm{MPa}$. Thermal treatment was performed at $482^{\circ} \mathrm{C}$ with $4 \mathrm{~h}$ holding. Tensile strain at break amounted to $12 \pm 2 \%$. Rockwell hardness test was conducted in conformity with DIN EN ISO 6508-1. Specimen hardness was equal to $41 \mathrm{HRC}$. Thermal conductivity of the specimens after fabrication and thermal treatment was: in horizontal plane $15.7 \pm 0.8 \mathrm{~W} /\left(\mathrm{m} \cdot{ }^{\circ} \mathrm{C}\right)$, in vertical plane $15.8 \pm 0.8 \mathrm{~W} /\left(\mathrm{m}^{\circ}{ }^{\circ} \mathrm{C}\right)$. Specific thermal capacity was equal to $470 \pm 20 \mathrm{~J} /\left(\mathrm{kg} \cdot{ }^{\circ} \mathrm{C}\right)$. There was a channel inside the implant with lateral holes for drug introduction (Figure 2 (a)).

Experimental investigations have been carried out on 6 Soviet Chinchilla rabbits aged 6-8 months and weighing $3.12 \pm 0.35 \mathrm{~kg}$. All animals underwent shin amputation at the border of the upper third under general anesthesia. Soft tissues were closed in layers by catgut sutures. Then, a bone marrow canal was enlarged to $4.5 \mathrm{~mm}$ by drilling, $5 \mathrm{~mm}$-implant was screwed in the tibia stump, and an abutment attached (Figure 2 (b)). The segment was further fixed by llizarov apparatus consisting of two supporting elements. For this purpose, the wires were crossed through the proximal metaepiphysis of the tibia and distal part of the abutment, distal wires had bulb tips (Figure 2 (c)). llizarov apparatus was demounted 6 weeks later.

Animals have been clinically observed throughout the experiment: their general condition, the limb function, soft tissue condition in the wire region were monitored. Control radiography was performed using portable TOSHIBA Rotanode E7239 X-ray apparatus (Toshiba, Japan) prior to the operation and at 1, 21, 42, 84 days following the operation.

The work was performed in accordance with ethical principles established by European Convention for the Protection of Vertebrata used for Experimental and other Scientific Purposes (the Convention was passed in Strasburg, March 18, 1986, adopted in Strasburg, June 15, 2006) and approved by Ethics Committee of the Russian Ilizarov Scientific Center for Restorative Traumatology and Orthopaedics. Animals were euthanized 12 weeks after the operation by way of barbiturate overdose.

Fixation of the tibia with the integrated implant was implemented in paraform-glutaraldehyde fixator $(2 \%$ paraform, $2 \%$ glutaraldehyde in phosphate buffer, $\mathrm{pH} 7.4$ ) at $4^{\circ} \mathrm{C}$. Seven days later, the bone was sawn in the longitudinal direction so that the integrated implant with the exposed surface on the bone section remained in one fragment. Bone sections with the implant were dehydrated in ethanol at increasing concentrations (from 70 to $100 \%$ ), embedded in camphene, and dried in the

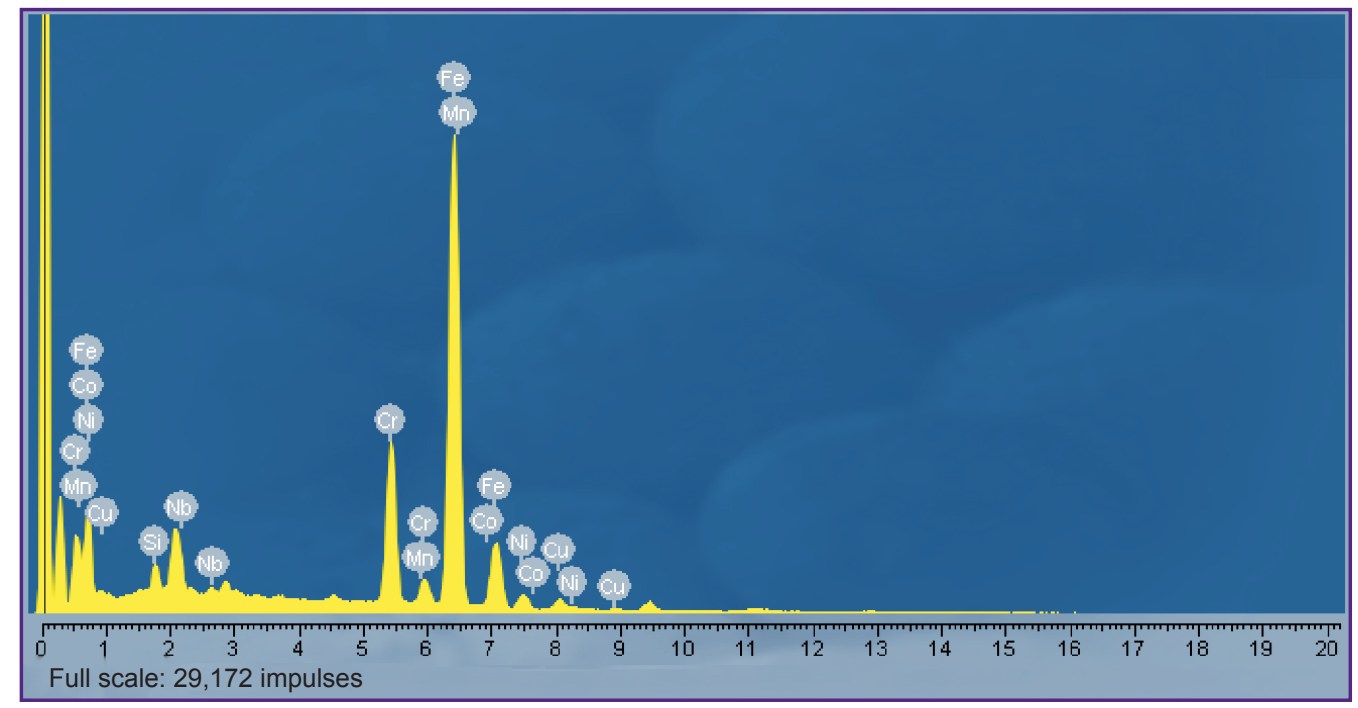

Figure 1. A sum element spectrum, obtained by an X-ray electron probe microanalysis of the implanted specimen 


\section{BIOMEDICAL INVESTIGATIONS}
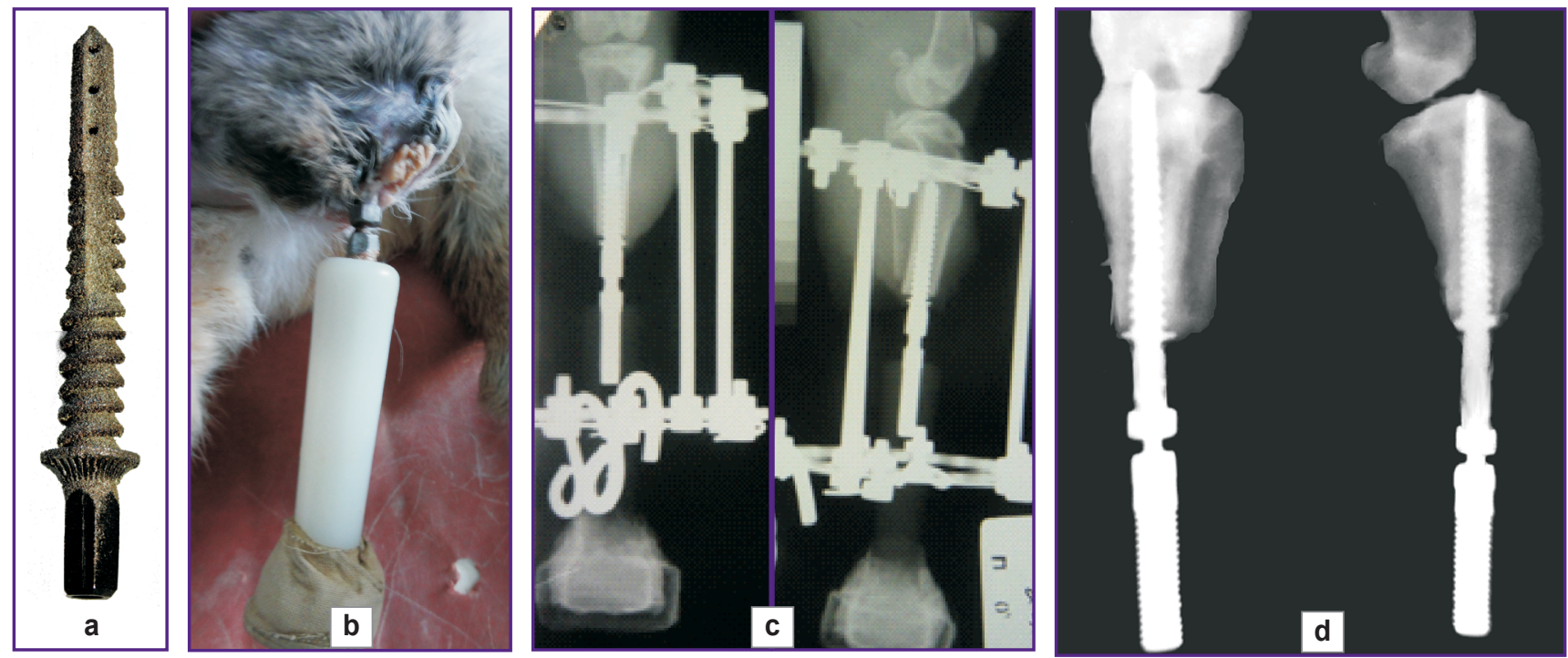

Figure 2. Implantation of the tubular bone stump at various stages of the experiment: (a) general implant view; (b) plastic abutment; (c) radiographs of the limb after operative intervention; (d) radiographs of the rabbit shins 12 weeks after the operation

air. The obtained preparations were mounted on the electroconductive substrate and coated with platinum and palladium ions in IB-6 ionic vacuum evaporator (Eiko, Japan). The preparations were examined under the JSM-840 scanning electron microscope (Jeol, Japan), obtaining the image in the mode of secondary electrons. Concentration of calcium and phosphorus in the tissue substrate adhered to the surface of the implant metal constructions was determined using INCA Energy 200 X-ray electron probe microanalyzer (Oxford Instruments, UK), mounted on the JSM-840 scanning electron microscope. The results of the investigations were obtained in the form of elemental maps (Start Map) and data of quantitative element analysis in weight percent.

Tibia sawn sections without implant were decalcified in Richman-Gelfand-Hill mixture, dehydrated in spirits with increasing concentration and embedded in paraffin. Longitudinal histological sections were stained with hematoxylin and eosin. Histotopographic sections 7-8 $\mu \mathrm{m}$ thick were obtained using a sliding microtome (Reichard, Germany), and stained with hematoxylin and eosin.

Light optical microscopic examination of the histological tibia preparations was performed using AxioScope A1 stereomicroscope and AxioCam IC 5 digital camera complete with Zen blue software (Carl Zeiss Microlmaging $\mathrm{GmbH}$, Germany).

Results. The clinical condition of rabbits was satisfactory throughout the experiment. In the first three days edema in the stump area was revealed in all animals. In three rabbits suppurative inflammation of the soft tissues around the implant was observed during 10-14 days. It was arrested by antibiotic therapy during $7-10$ days (Cefazolin $0.05 \mathrm{~g} / \mathrm{kg}$ ). Weight-bearing function of the limb restored, as a rule on days 4-5 after the operation and remained throughout the experiment. The given technology enabled for the first time restoration of the amputated limb function in the early postoperative period.

On the radiograms, formation of the channel around the implant and bone tissue resorption were found in three rabbits by week 6 , and by week 12 a marked osteoporosis of the cortical plate was observed. In one case the tibia fractured at the level of its upper third.

The signs of osseointegration at the implant-bone tissue junction were found in three other rabbits 12 weeks later. It manifested itself in retaining the density and thickness of the cortical plate. There were no signs of bone resorption around the implant. In the projection of the bone marrow canal in the regions between the implant and cortical plate shadows of increased radioopacity were visualized being the evidence of endosteal osteogenesis (Figure 2 (d)).

Histological examinations in these rabbits showed that 12 weeks after implantation of the metal construction into the tibia bone marrow canal there was no evidence of osteoporosis in the compact plate (Figure 3 (c)). The compact plate bone tissue tightly adhered to the implant in the tibia distal part and had a typical structure over the whole length (Figure 3 (a), (c)). In other regions between the implant and cortical plate there was a gap, reproducing the cone-shape form of the implanted construction, in which there was noted formation of trabecular bone of mesobrochate structure connecting the inner surface of the compact plate and the surface of the implant embedded into the bone (Figure $3(\mathrm{f})$ ). Intertrabecular intervals were mainly filled with red bone marrow.

Homogeneously distributed tissue substrate was 

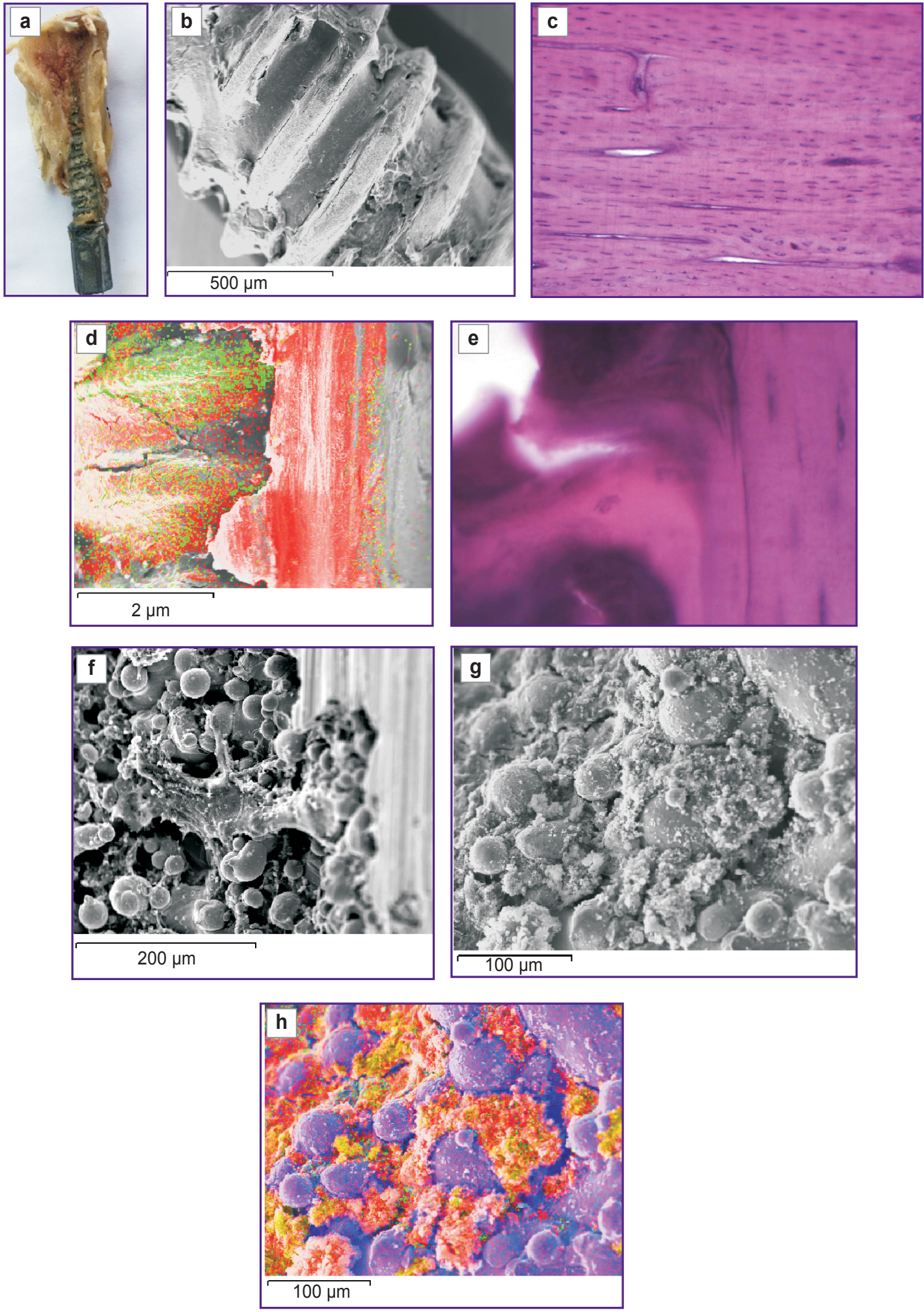

Figure 3. Formation of the "bone-implant" block on week 12 of the experiment: (a) a sawn section of the rabbit tibia with the embedded implant; (b) implant surface with adhered tissue substrate; scanning electron microscopy (SEM), ×22; (c) compact plate; staining with hematoxylin and eosin, $\times 63$; (d) electron image of the compact plate and implant contact; SEM, $\times 22$; the map of $\mathrm{Ca}$ (red) and P (green) distribution in the "bone-implant" block; (e) trabecular bone in the gap between the bone and implant; staining with hematoxylin and eosin, $\times 400$; (f) bone trabecula, hemopoietic bone marrow in the gap region between the compact plate and screw construction; SEM, $\times 150 ;(\mathrm{g})$, (h) adhesion of bone matrix to the implant surface: $(\mathrm{g})$ SEM, $\times 350$; (h) a map of X-ray electron probe microanalysis of $\mathrm{Ca}$ (red) and $\mathrm{P}$ (green) distribution over the implant surface (implantation material $\mathrm{Fe}-$ blue), $\times 350$ 


\section{BIOMEDICAL INVESTIGATIONS}
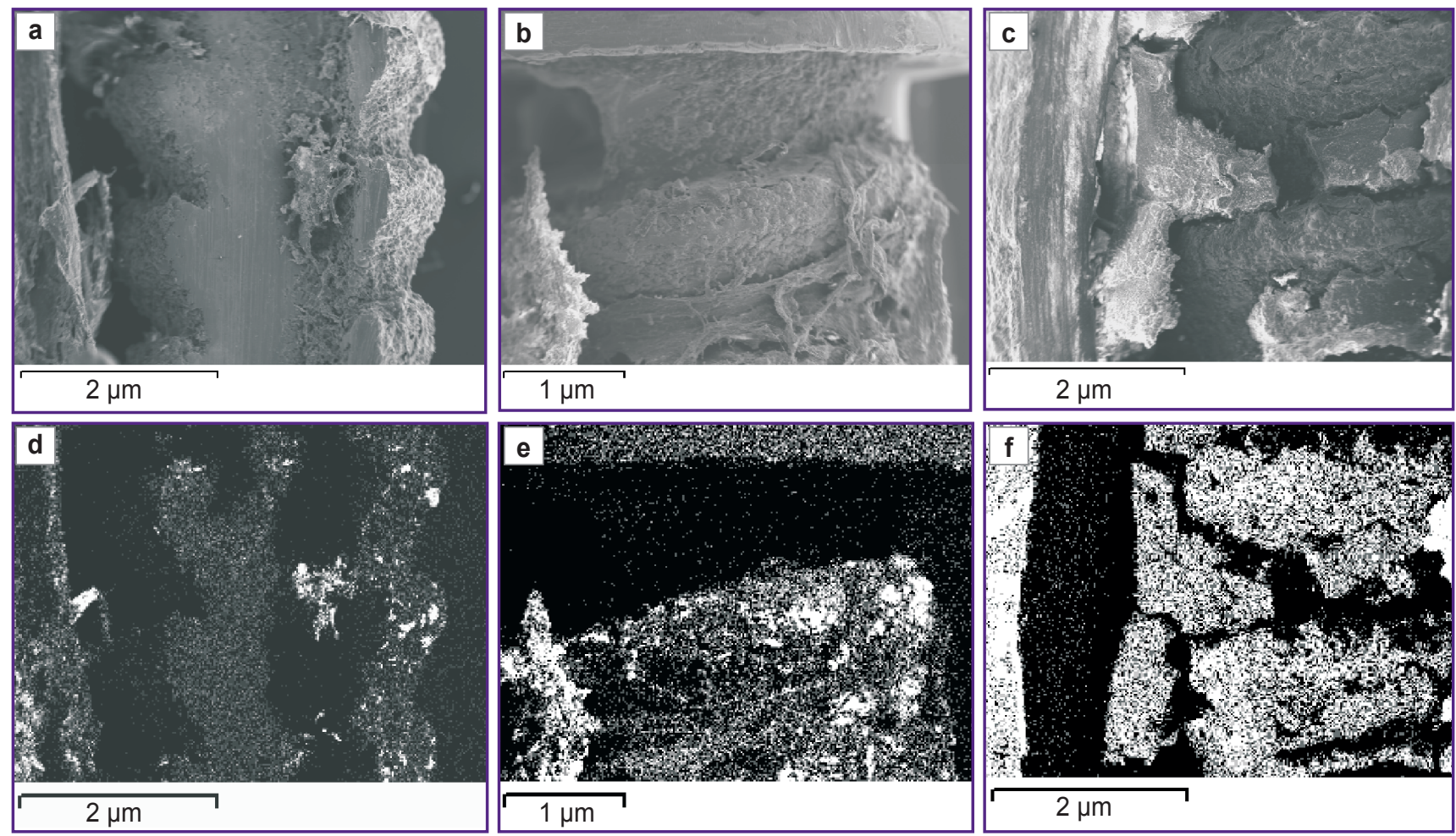

Figure 4. Adhesion of neogenic reticulofibrous bone tissue to the surface of the implanted endosteal metal construction: (a)(c) surface areas of the implant in its lower, upper and middle third; SEM, $\times 22$; (d)-(f) maps of Ca distribution on the implant surface in the lower, upper and middle thirds, respectively; X-ray electron probe microanalysis, $\times 22$

detected on threaded ribs and in the zones of the implant threaded grooves (Figure 3 (a), (b)).

$\mathrm{X}$-ray electron probe microanalysis of the tissue substrate adhered to the implant surface showed presence of $\mathrm{Ca}$ and $\mathrm{P}$ in it (Figure $3(\mathrm{~d}),(\mathrm{e}),(\mathrm{g}),(\mathrm{h})$ ), that spoke of forming a neogenic bone tissue in the examined specimen.

Quantitative investigations found that $\mathrm{Ca}$ content in the neogenic bone tissue on the implant surface amounted to $7-9 \%$ at the ratio of $\mathrm{Ca} / \mathrm{P}$ from 0.3 to 1 , which corresponded to reticulofibrous bone tissue by the degree of mineralization.

This fact was supported by the scanning electron microscopy results. Bone trabeculae were revealed both in the grooves and on the ribs of the threaded intraosseous construction, intimately connected by a fibrous component with the implant surface (See Figure 3 (e)). Osteogenic cells and cells of the hemopoietic bone marrow were present in the tissue substrate, which also confirmed the availability of neogenic bone tissue on the surface of the metal construction.

Similar findings were typical for all areas of the implanted construction (Figure 4).

Discussion. Previously conducted investigations in vitro proved that one of the main components in implantation of screw constructions is to provide formation of the adequate "implant-bone" complex possessing a sufficient strength to endure mechanical loads [1]. Our study demonstrated that application of additive technologies makes it possible to assign the necessary implant parameters (surface structuring, individual forms and sizes, and so on) to obtain a robust "implant-bone" block. Besides, the main concept of the traditional technology of intraosseous prosthetics consists in two-stage operation: at the first stage an implant is installed into intramedullary canal and then, 3-6 months later (when a robust "implant-bone" block is formed), an adapter for fixation of the prosthetic construction is attached to the implant through the skin incision. Treatment (including the period of rehabilitation) usually takes $6-18$ months $[2,11]$. Using our combined prosthetic technology with fixation of the implant by llizarov apparatus, the stability at the bone-implant junction and early load on the limb can be provided before osseointegration is completed.

Conclusion. The obtained preliminary results of using screw implants, fabricated by means of additive technologies from the stainless steel-based alloy showed the ability of their osseointegration. A neogenic bone tissue on the surface of the implanted construction is characterized by the mineral component content sufficient for a functional load already after 12 weeks of the experiment. It testifies to the perspectivity of applying additive technologies for creation of tubular bone implants from stainless steel.

Study Funding. The work was supported by the grant 
of the Russian Scientific Fund for implementation of project No.16-15-00176 "Establishing the mechanisms of osseointegration of medical implants on the basis of additive manufacturing with bioactive coatings".

Conflicts of interest. The authors declare no conflicts of interest.

\section{References}

1. Perikova M.G., Sirak S., Kazieva I., Martirosan A. Assessment of screw bioactive coatings of dental implants for a period of osseointegration (experimental morphological research). Sovremennye problemy nauki i obrazovaniya 2013; 2. URL: https://www.science-education.ru/ru/article/view?id=8686.

2. Shevtsov M.A., Galibin O.V., Yudintceva N.M., Blinova M.I., Pinaev G.P., Scherbina K.K., Shvedovchenko I.V., Pitkin M.R. Osseointegration in reconstructive surgery: contemporary state and perspectives of furhther development (review). Travmatologiya $i$ ortopediya Rossii 2012; 4(66): 126-134.

3. Dayer R., Rizzoli R., Kaelin A., Ammann P. Low protein intake is associated with impaired titanium implant osseointegration. J Bone Miner Res 2006; 21(2): 258-264, https://doi.org/10.1359/jbmr.051009.

4. Maïmoun L., Brennan T.C., Badoud I., DuboisFerriere V., Rizzoli R., Ammann P. Strontium ranelate improves implant osseointegration. Bone 2010; 46(5): 1436-1441, https://doi.org/10.1016/j.bone.2010.01.379.

5. Dayer R., Brennan T.C., Rizzoli R., Ammann P. PTH improves titanium implant fixation more than pamidronate or renutrition in osteopenic rats chronically fed a low protein diet. Osteoporos Int 2010; 21(6): 957-967, https://doi.org/10.1007/ s00198-009-1031-x.
6. de Vasconcellos L.M.R., Oliveira F.N., Leite D. de O., de Vasconcellos L.G.O., do Prado R.F., Ramos C.J., Graça M.L., Cairo C.A., Carvalho Y.R. Novel production method of porous surface $\mathrm{Ti}$ samples for biomedical application. J Mater Sci Mater Med 2012; 23(2): 357-364, https://doi.org/10.1007/s10856-011-4515-0.

7. Hagberg K., Brånemark R., Gunterberg B., Rydevik B. Osseointegrated trans-femoral amputation prostheses: prospective results of general and conditionspecific quality of life in 18 patients at 2-year followup. Prosthet Orthot Int 2008; 32(1): 29-41, https://doi. org/10.1080/03093640701553922.

8. Lambers F.M., Schulte F.A., Kuhn G., Webster D.J., Müller R. Mouse tail vertebrae adapt to cyclic mechanical loading by increasing bone formation rate and decreasing bone resorption rate as shown by time-lapsed in vivo imaging of dynamic bone morphometry. Bone 2011; 49(6): 1340-1350, https://doi.org/10.1016/j.bone.2011.08.035.

9. Baggi L., Cappelloni I., Di Girolamo M., Maceri F., Vairo G. The influence of implant diameter and length on stress distribution of osseointegrated implants related to crestal bone geometry: a three-dimensional finite element analysis. J Prosthet Dent 2008; 100(6): 422-431, https://doi. org/10.1016/s0022-3913(08)60259-0.

10. Sirak S.V., Kazieva I.E. Development of the construction of dental implants with the possibility of intraosseous administration of the drug for edema inflammation and strengthen the process of osseointegration in dental implantation. Sovremennye problemy nauki $i$ obrazovaniya 2013; 3. URL: https://www.science-education.ru/ru/article/ view?id=8834.

11. Cochran D.L. A comparison of endosseous dental implant surfaces. J Periodontol 1999; 70(12): 1523-1539, https://doi.org/10.1902/jop.1999.70.12.1523. 